\title{
The tomato 2-oxoglutarate-dependent dioxygenase gene SIF3HL is critical for chilling stress tolerance
}

Tixu Hu', Yuqin Wang ${ }^{1}$, Qiqi Wang ${ }^{1}$, Ningning Dang ${ }^{1}$, Ling Wang ${ }^{2}$, Chaochao Liu' ${ }^{2}$ Jianhua Zhu ${ }^{2,3}$ and Xiangqiang Zhan ${ }^{1}$

\begin{abstract}
Low temperature is a major stress that severely affects plant development, growth, distribution, and productivity. Here, we examined the function of a 2-oxoglutarate-dependent dioxygenase-encoding gene, SIF3HL, in chilling stress responses in tomato (Solanum lycopersicum cv. Alisa Craig [AC]). Knockdown (KD) of SIF3HL (through RNA interference) in tomato led to increased sensitivity to chilling stress as indicated by elevated levels of electrolyte leakage, malondialdehyde (MDA) and reactive oxygen species (ROS). In addition, the KD plants had decreased levels of proline and decreased activities of peroxisome and superoxide dismutase. The expression of four cold-responsive genes was substantially reduced in the KD plants. Furthermore, seedling growth was significantly greater in AC or SIF3HLoverexpression plants than in the KD plants under either normal growth conditions with methyl jasmonate (MeJA) or chilling stress conditions. SIF3HL appears to positively regulate JA accumulation and the expression of JA biosynthetic and signaling genes under chilling stress. Together, these results suggest that SIF3HL is a positive regulator of chilling stress tolerance and functions in the chilling stress tolerance pathways, possibly by regulating JA biosynthesis, JA signaling, and ROS levels.
\end{abstract}

\section{Introduction}

Cold stress is among the main environmental stresses limiting plant geographical distribution, growth and yield ${ }^{1}$. Cold stress can be divided into two categories: chilling stress $\left(0-20^{\circ} \mathrm{C}\right)$ and freezing stress $\left(<0^{\circ} \mathrm{C}\right)$. Chilling-sensitive plants, such as tomato, cucumber, and sweet pepper, can suffer from cold injury and reduced productivity when exposed to low temperature $\left(0-12{ }^{\circ} \mathrm{C}\right)$. Enhancing the low temperature tolerance of chillingsensitive plants is thus a major target for plant breeders ${ }^{2}$. Cold acclimation enables many temperate plants to obtain

Correspondence: Jianhua Zhu (jhzhu@umd.edu) or Xiangqiang Zhan (zhanxq77@nwsuaf.edu.cn)

${ }^{1}$ State Key Laboratory of Crop Stress Biology for Arid Areas and College of Horticulture, Northwest A\&F University, No. 3, Taicheng Road, 712100 Yangling, Shaanxi, China

${ }^{2}$ School of Biotechnology, Jiangsu University of Science and Technology, Zhenjiang, Jiangsu, China

Full list of author information is available at the end of the article. chilling tolerance after being exposed to low temperatures $^{3}$. Cold acclimation involves many physiological and biochemical processes, including changes in membrane stability $^{4}$, calcium fluxes ${ }^{5}$, and changes in cell wall properties $^{6}$. These changes are related to the transcript levels of a number of cold-regulated genes in plants ${ }^{7}$.

Many cold-induced pathways are genetically activated to protect plants from cold stress. To date, most studies on this topic have been focused on the Inducer of CBF Expression 1 (ICE1-CBF) C-Repeat-Binding Factors (COR) (cold regulated) signaling pathway ${ }^{8,9}$. The function of the ICE1-CBF-COR pathway appears to be conserved among plant species ${ }^{10,11}$. It comprises the core components ICE1, CBF transcription factors, and diverse COR proteins, which are generally inducible by cold stress.

CBF proteins/transcription factors belong to the AP2/ ERF (APETALA2/Ethylene-Responsive Factor)-type family of transcription factors. These CBF proteins/

\section{(c) The Author(s) 2019}

(c) (i) Open Access This article is licensed under a Creative Commons Attribution 4.0 International License, which permits use, sharing, adaptation, distribution and reproduction c. in any medium or format, as long as you give appropriate credit to the original author(s) and the source, provide a link to the Creative Commons license, and indicate if changes were made. The images or other third party material in this article are included in the article's Creative Commons license, unless indicated otherwise in a credit line to the material. If material is not included in the article's Creative Commons license and your intended use is not permitted by statutory regulation or exceeds the permitted use, you will need to obtain permission directly from the copyright holder. To view a copy of this license, visit http://creativecommons.org/licenses/by/4.0/. 
transcription factors can bind to promoters containing Crepeat/dehydration-responsive element (DRE) (G/ ACCGAC) and regulate the transcription of downstream $C O R$ genes under low temperature ${ }^{12-14}$. Three $C B F$ genes in Arabidopsis are transiently induced by cold stress and rapidly reach their maximal levels of expression under this stressor $^{15,16}$. Ectopic expression of the tomato $S l C B F 1$ in Arabidopsis has been shown to increase freezing tolerance $^{17}$. The expression of $S l C B F 1$ and $S l C B F 2$ is induced after $3 \mathrm{~h}$ at $10^{\circ} \mathrm{C}$ during cold acclimation in tomato ${ }^{18}$. AtICE1 encodes an MYC-type basic helix-loop-helix transcription factor that binds to the cis-element CANNTG in the $A t C B F 3$ promoter and activates $A t C B F 3$ expression under chilling stress ${ }^{19,20}$. As a homolog of AtICE1, AtICE2 activates AtCBF1 expression during chilling stress ${ }^{21}$. SIICE1 can enhance chilling tolerance and increase the expression of SlCBF1 and SIDRCi7 during chilling stress in tomato ${ }^{22}$. These data suggest that ICEs play crucial roles in the plant response to chilling stress. In addition, ICE is regulated negatively or positively by many other genes, such as HOS1, OST1, and MAPKs. HOS1 encodes a RING finger ubiquitin E3 ligase that interacts with ICE1 and promotes ICE1 degradation by the ubiquitination/proteasome pathway $^{23,24}$. OST1 encodes a Ser/Thr protein kinase that positively regulates ICE1 protein stability by phosphorylating ICE1 at Ser278 ${ }^{25,26}$. MAPK3 and MAPK6 can phosphorylate ICE1, leading to its degradation ${ }^{27}$.

Phytohormones involved in tolerance to abiotic stresses include abscisic acid (ABA), which is important in regulating plant stress signaling ${ }^{28,29}$. Several reports show that jasmonate (JA) is also important in abiotic stress responses ${ }^{30}$. JA is a class of fatty acid-derived phytohormone. The first step of JA biosynthesis entails the oxygenation of linolenic acid and involves many JA biosynthetic enzymes, including LOX (13-lipoxygenase), allene oxide synthase (AOS), allene oxide cyclase (AOC), and OPR [(9S,13S)-12-oxo-phytodienoic acid reductase $]^{31}$. JA content in $Z m L O X 8$ mutant leaves is reduced in response to mechanical wounding ${ }^{32}$. JA is involved in a series of physiological and stress-related processes, such as stomatal closure and the detoxification activity of antioxidant enzymes, which can enhance plant tolerance to environmental stresses ${ }^{33,34}$. JAZ (JA ZIM-domain) proteins belong to the TIFY family and are important for the regulation of JA signaling. In the absence of bioactive JA, JAZs suppress the transcript levels of downstream genes, including MYC2. Under increased levels of JA, the F-box protein COI1 (CORNATINE INSENSITIVE1) interacts with JAZ proteins and promotes JAZ protein degradation through the ubiquitin degradation pathway $^{35,36}$. JAZ proteins interact with MYB21 and MYB24, which regulate downstream gene expression ${ }^{37}$. JAZ1 and JAZ4 proteins interact with ICE1, which can regulate the transcription of downstream genes and influence freezing tolerance in Arabidopsis ${ }^{38}$. Overexpression of OsbHLH148 increases drought stress tolerance in rice through OsbHLH148-OsJAZ-OsCOI1-JA signaling ${ }^{39}$. Suppression of OsJAZ9 in rice reduces salt stress tolerance by regulating the JA signaling pathways ${ }^{40}$. The findings of one study suggested that the level of endogenous JA was increased under chilling stress in rice ${ }^{41}$. In addition, previous studies have shown that JA acts as a key signal in the ICE-CBF pathway that increases cold tolerance in Arabidopsis. Exogenous JA was found to significantly improve freezing tolerance in Arabidopsis, and the suppression of JA biosynthesis and signaling increased Arabidopsis sensitivity to freezing stress ${ }^{38}$. Furthermore, JA has been shown to activate the CBF pathway and increase chilling stress tolerance in tomato ${ }^{42}$.

Members of the 2-oxoglutarate $\mathrm{Fe}(\mathrm{II})$-dependent oxygenase (2-OG oxygenase) superfamily, which is the second largest enzyme family, are involved in various metabolic processes, such as plant hormone biosynthesis $^{43}$. One member of this family is involved in the biosynthesis of gibberellins ${ }^{44}$. AtDMR6 (Arabidopsis downy mildew-resistant 6) belongs to the 2-OG oxygenase superfamily; its expression is induced by pathogen attack and salicylic acid (SA) treatment ${ }^{45}$. AtDMR6 catalyzes the hydrolysis of SA to 2,5-dihydroxybenzoic acid ${ }^{46}$.

In the present study, we isolated a tomato gene, SIF3HL, belonging to the 2-OG oxygenase superfamily that contains a 2OG-FeII-Oxy domain. SlF3HL, which has its highest sequence homology with AtDMR6, is responsive to chilling stress. Tomato plants with reduced expression of SlF3HL (achieved via knockdown through RNA interference) were found to be hypersensitive to chilling stress. We showed that SlF3HL positively regulates chilling stress tolerance, possibly by modulating JA biosynthesis, the expression of JA signaling molecules (such JAZ proteins) and the accumulation of reactive oxygen species (ROS) under chilling stress conditions.

\section{Materials and methods}

\section{Growth conditions and analysis of chilling stress tolerance} in tomato

Tomato (Solanum lycopersicum cv. Alisa Craig, AC) seeds of AC and SlF3HL transgenic lines were sown in black plastic pots containing soil, perlite, and vermiculite $(\mathrm{v} / \mathrm{v} / \mathrm{v}=2: 1: 1)$. The seedlings were grown under normal conditions $\left(25^{\circ} \mathrm{C}, 60-65 \%\right.$ relative humidity, 16-h day/8-h night). One-month-old tomato plants were used in the subsequent experiments. For the chilling tolerance assays, plants were transferred to a growth chamber at $4{ }^{\circ} \mathrm{C}$ and maintained under the same relative humidity and photoperiod as during their previous growth. For treatment with MeJA and DIECA (JA biosynthesis inhibitor sodium diethyldithiocarbamate 
trihydrate), seeds of AC and SlF3HL transgenic lines were surface-sterilized and sown on 1/2 MS (MurashigeSkoog) medium plates for germination under normal conditions $\left(25^{\circ} \mathrm{C}, 60-65 \%\right.$ relative humidity, 16-h day/8-h night). After 6 days, seedlings of similar size were transferred to $1 / 2 \mathrm{MS}$ medium plates supplemented with 0 or $5 \mu \mathrm{M}$ MeJA or with 0 or $10 \mu \mathrm{M}$ DIECA and placed in a $4{ }^{\circ} \mathrm{C}$ growth chamber. Other seedlings were treated in the same manner but were grown at $25^{\circ} \mathrm{C}$ in a separate growth chamber. After 7 days of these treatments, the fresh weights, root lengths, and hypocotyl lengths of the seedlings were measured.

\section{RNA extraction and quantitative real-time PCR (qPCR) analysis}

Total RNA was extracted from various tissues of the tomato plants using Trizol (Invitrogen, USA). cDNA was synthesized from total RNA using a cDNA synthesis kit (Toyobo Bio-Technology, China) following the manufacturer's instructions. qPCR was carried out on a Bio-Rad CFX96 ${ }^{\mathrm{TM}}$ instrument (Bio-Rad, USA) following the manufacturer's instructions. The specific primers are listed in Table S1. The actin gene (Accession No. BT013524) was used as the internal control. The transcript level of specific genes was measured using the cycle threshold (Ct) $2^{-\Delta \Delta C t} \operatorname{method}^{47}$.

\section{Relative electrical conductivity (REC) assays}

The REC was measured as previously described ${ }^{48}$. Ten leaf disks (each $0.6 \mathrm{~cm}$ in diameter) from each line were harvested and placed in a glass tube containing $10 \mathrm{ml}$ of deionized water. After the glass tube was shaken at 100 cycles per min for 30 min under normal laboratory conditions, the initial electrical conductivity $\left(C_{1}\right)$ was measured with a conductivity meter (Mettler Toledo FE30, Switzerland). Then, the glass tube containing leaf segments in distilled water was boiled for $30 \mathrm{~min}$. The final electrical conductivity $\left(C_{2}\right)$ was measured after cooling the tube to ambient temperature. The electrical conductivity $\left(C_{0}\right)$ of the deionized water was measured and used as the blank. REC was calculated as $\left(C_{1}-C_{0}\right) /\left(C_{2}-C_{0}\right) \times 100 \%$.

\section{Malondialdehyde (MDA) content measurement}

The level of MDA was determined using the thiobarbituric acid method as previously described ${ }^{49}$. Leaf samples (approximately $0.3 \mathrm{~g}$ per sample) were collected from the second leaf from the top of 1-month-old tomato plants grown under normal conditions or under chilling stress. Samples were ground with $5 \mathrm{ml}$ of ice-cold $10 \%$ TCA (trichloroacetic acid). The homogenates were centrifuged at $12,000 \times g$ for $10 \mathrm{~min}$ at $4{ }^{\circ} \mathrm{C}$. A 2 -ml volume of the supernatant and $2 \mathrm{ml}$ of $10 \%$ TCA containing $0.6 \%$ thiobarbituric acid were mixed together and boiled for
15 min. After the mixture was cooled to ambient temperature, the homogenate was centrifuged for $10 \mathrm{~min}$ at $10,000 \times g$. Absorbance was recorded at 450, 532, and $600 \mathrm{~nm}$ using an Infinite M200 microplate reader (Tecan, Switzerland).

\section{Proline content measurement}

The level of proline was determined using the acid ninhydrin method as previously described ${ }^{50}$. Leaf samples (approximately $0.3 \mathrm{~g}$ per sample) were ground with $5 \mathrm{ml}$ of $3 \%$ sulfosalicylic acid and boiled for $30 \mathrm{~min}$ with shaking. After cooling the suspension to ambient temperature, the suspension was centrifuged for $10 \mathrm{~min}$ at $12,000 \times g$. A $1-\mathrm{ml}$ volume of the supernatant, $1 \mathrm{ml}$ of acid ninhydrin, and $1 \mathrm{ml}$ of acetic acid were mixed together and boiled for $60 \mathrm{~min}$. After cooling the mixture to ambient temperature, the preparation and $3 \mathrm{ml}$ of toluene were mixed together and centrifuged for $10 \mathrm{~min}$ at $12,000 \times g$. Subsequently, $150 \mu \mathrm{l}$ of the toluene phase was recovered, and its absorbance at $520 \mathrm{~nm}$ was measured with an Infinite M200 microplate reader. The level of proline was calculated using a standard curve relating proline concentration to absorbance.

\section{$\mathrm{O}_{2}{ }^{-}$content measurement}

The level of $\mathrm{O}_{2}{ }^{-}$was determined as previously described $^{51}$. Leaf samples (approximately $0.3 \mathrm{~g}$ per sample) were ground with $2 \mathrm{ml}$ of ice and precooled $50 \mathrm{mM}$ phosphate buffer solution (PBS, $\mathrm{pH} 7.8$ ) and then centrifuged at $12,000 \times g$ for $10 \mathrm{~min}$ at $4{ }^{\circ} \mathrm{C}$. A $1-\mathrm{ml}$ volume of the supernatant, $1 \mathrm{ml}$ of $10 \mathrm{mM}$ hydrochloride hydroxylamine, and $3 \mathrm{ml}$ of PBS were mixed together and incubated for $20 \mathrm{~min}$ at $25^{\circ} \mathrm{C}$. Then, the reaction mixture, $1 \mathrm{ml}$ of $7 \mathrm{nM} \alpha$-naphthylamine and $1 \mathrm{ml}$ of $17 \mathrm{nM} \mathrm{p}$ aminobenzenesulfonic acid were mixed together and incubated for $30 \mathrm{~min}$ at $30{ }^{\circ} \mathrm{C}$. Finally, the absorbance at $530 \mathrm{~nm}$ of $200 \mu \mathrm{l}$ of the reaction mixture was determined using an Infinite M200 microplate reader. The $\mathrm{O}_{2}{ }^{-}$content was calculated using a standard curve relating $\mathrm{O}_{2}{ }^{-}$ concentration to absorbance.

\section{$\mathrm{H}_{2} \mathrm{O}_{2}$ detection}

$\mathrm{H}_{2} \mathrm{O}_{2}$ was detected as previously described ${ }^{52}$. Leaves of plants of the AC and transgenic tomato lines were stained with 3,3'-diaminobenzidine to determine the level of $\mathrm{H}_{2} \mathrm{O}_{2}$ under normal and low-temperature conditions. Four-week-old plants of the AC and transgenic lines were transferred to growth chambers at 25 or $4{ }^{\circ} \mathrm{C}$. After 5 days, leaves were soaked in $1 \mathrm{mg} / \mathrm{ml} \mathrm{DAB}\left(3,3^{\prime}\right.$-diaminobenzidine) in $50 \mathrm{mM}$ Tris-base ( $\mathrm{pH} 5.0$ ). The plants were then incubated for $24 \mathrm{~h}$ in the dark at $25^{\circ} \mathrm{C}$. Chlorophyll was removed by incubation with $70 \%$ ethanol before $\mathrm{H}_{2} \mathrm{O}_{2}$ was assessed. 

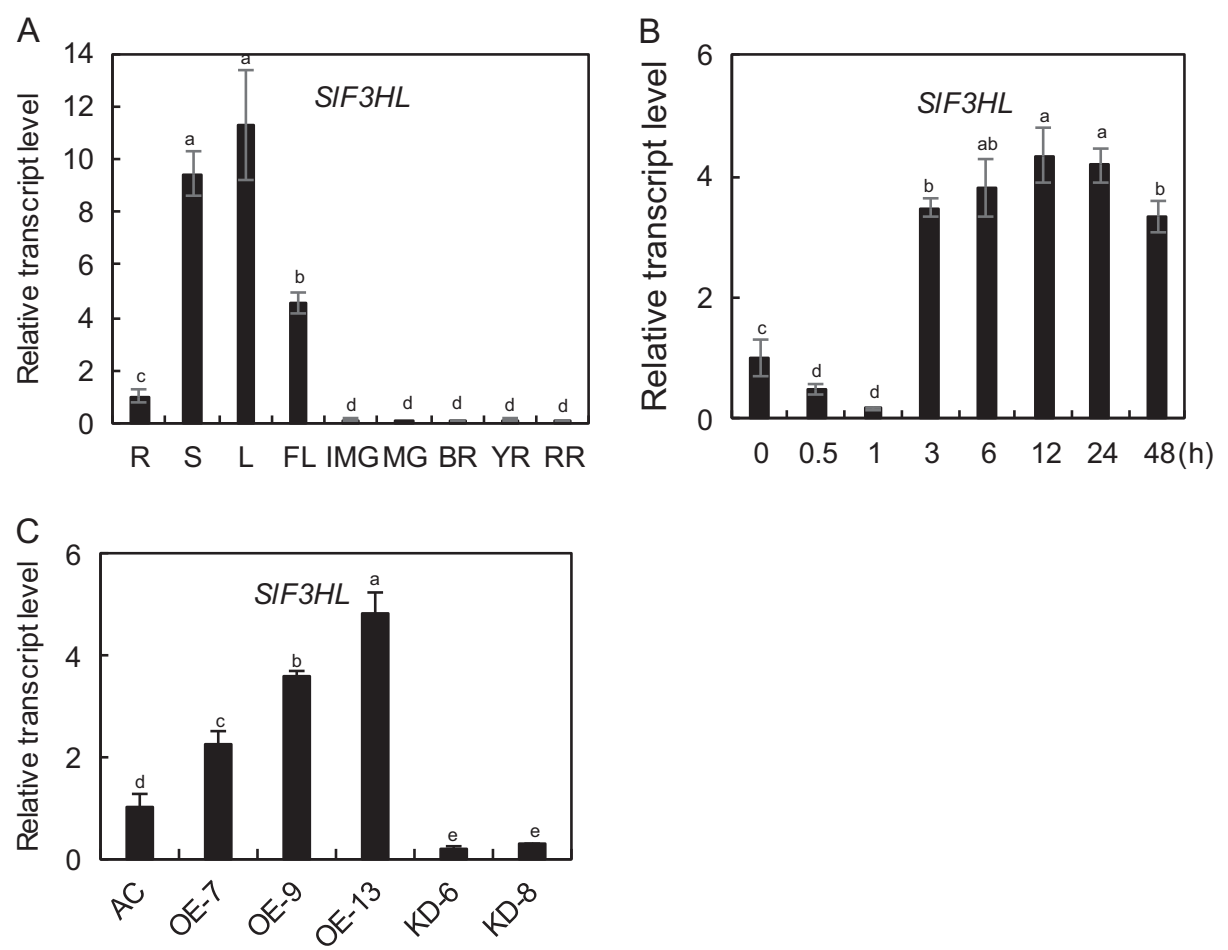

Fig. 1 qRT-PCR analysis of transcript abundance of SIF3HL. a The transcript levels of SIF3HL in different tomato organs: R, Root; S, Stem; L, Leaf; FL, Flower; IMG, Immature fruit; MG, Mature green fruit; BR, Breaker stage fruit; YR, Yellow stage fruit; RR, Red ripe stage fruit; $\mathbf{b}$ The transcript abundance of SIF3HL in response to chilling stress at $4^{\circ} \mathrm{C}$; $\mathbf{c}$ SIF3HL expression in young leaves of the wild type (AC) line, three SIF3HL-OE (overexpression) lines, and two SIF3HL-KD (knockdown) lines. The data are presented as the mean $\pm \mathrm{SD}(n=3)$. Values with different letters significantly differ according to analysis of variance (ANOVA) and least significant difference (LSD) tests $(p<0.05)$

\section{Measurement of antioxidant enzyme activities}

Antioxidant enzymes activities were measured as previously described ${ }^{53}$. In brief, leaf samples (approximately $0.2 \mathrm{~g}$ per sample) were ground with $2 \mathrm{ml}$ of ice and added to precooled $50 \mathrm{mM}$ PBS ( $\mathrm{pH} 7.8$ ) containing $1 \mathrm{mM}$ EDTA (ethylenediaminetetraacetic acid), 0.1\% (v/v) Triton X-100, and 1\% (w/v) PVP (polyvinylpolypyrrolidone). The suspension was centrifuged at $12,000 \times g$ for $10 \mathrm{~min}$ at $4{ }^{\circ} \mathrm{C}$. The supernatants were then used for measurement of the activities of the antioxidant enzymes SOD (superoxide dismutase) and POD (peroxidase).

\section{JA content measurement}

Leaf samples (approximately $0.2 \mathrm{~g}$ per sample) were ground in liquid nitrogen. The powdered leaf samples were resuspended in $2 \mathrm{ml}$ of extraction solution containing $0.4 \mathrm{ml}$ of methanol, $1.58 \mathrm{ml}$ of isopropanol and $0.02 \mathrm{ml}$ of glacial acetic acid. A $1.5-\mathrm{ml}$ volume of the suspension was centrifuged at $12,000 \times g$ for $10 \mathrm{~min}$ at $4{ }^{\circ} \mathrm{C}$. The supernatant was collected and concentrated under a nitrogen stream. The concentrated samples were then redissolved in $200 \mu \mathrm{l}$ of methanol and filtered by a $0.22-\mu \mathrm{m}$ PTFE filter. The content of JA was analyzed by using ultrahigh-performance liquid chromatography coupled to electrospray ionization tandem spectrometry (UHPLC/ESI-MS/MS) as previously described ${ }^{54}$.

\section{Results}

\section{Expression patterns of SIF3HL in tomato}

In a previous study, SlF3HL (GenBank Accession No. NP_001233840 and SGN Accession No. Solyc03g080190) was identified as a gene encoding a 2-oxoglutaratedependent dioxygenase protein (a member of the 2-OG oxygenase superfamily), which shares the highest sequence similarity with the AtDMR6 protein $^{55}$. We examined the expression patterns of SlF3HL in various tomato organs using qRT-PCR analysis. As shown in Fig. 1a, the transcript levels of SlF3HL were higher in leaves, stems, and flowers than in roots and were at lowest at all developmental stages of fruits. We also determined the transcript abundance of $S l F 3 H L$ in response to chilling treatment $\left(4^{\circ} \mathrm{C}\right)$ in tomato. The expression of SlF3HL was substantially decreased during the first $1 \mathrm{~h}$ of chilling treatment and then increased at and beyond $3 \mathrm{~h}$ of chilling treatment (Fig. 1b). These data suggest that SlF3HL may be involved in chilling stress responses in tomato. 

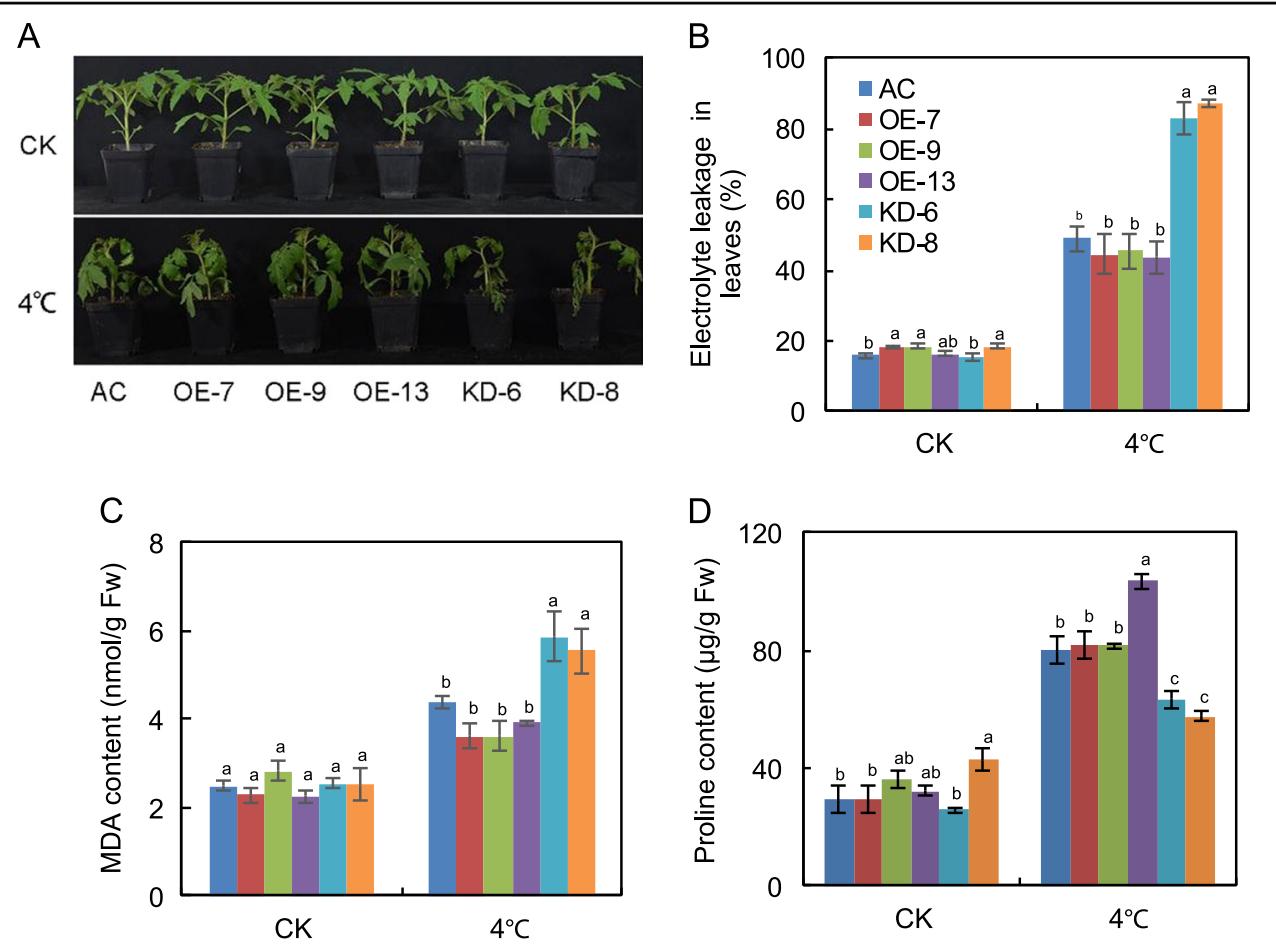

Fig. 2 SIF3HL is important for chilling stress tolerance. a The phenotypes of plants of the AC and SIF3HL transgenic lines treated with or without chilling stress for 5 days; $\mathbf{b}$ Chilling tolerance of plants shown in A as determined by leaf electrolyte leakage assays; $\mathbf{c}$ MDA content in leaves of plants shown in a. $\mathbf{d}$ Proline content in leaves of plants shown in $\mathbf{a} C K$, normal growth conditions. The data are presented as the mean \pm SD $(n \geq 5)$. Values with different letters under normal or chilling stress conditions significantly differ according to ANOVA and LSD tests $(p<0.05)$

\section{Generation of SIF3HL transgenic plants}

To determine the role of SlF3HL in chilling stress responses in tomato, we generated 25 SlF3HL-overexpression (OE) transgenic tomato plants and 20 RNA interference (KD) transgenic tomato plants. Three independent $\mathrm{OE}$ and two independent KD transgenic lines were chosen for further analysis. The expression of SIF3HL was substantially higher in the OE lines and lower in the KD lines than in AC (Fig. 1c). The transcript levels of SlF3HL in leaves of the OE-7, OE-9, and OE-13 lines were 2.2-fold, 3.5-fold, and 4.8-fold higher than those in the AC leaves, whereas SIF3HL transcript levels were 0.2fold lower in the KD-6 leaves and 0.3-fold lower in KD-8 leaves than in the $\mathrm{AC}$ leaves (Fig. 1c).

\section{SIF3HL is important for chilling stress tolerance}

To determine whether alteration of SlF3HL expression affects chilling stress tolerance, we treated 5-week-old transgenic and wild-type plants at $4{ }^{\circ} \mathrm{C}$ for 7 days. Following this chilling stress, leaves were severely wilted on the KD plants but only slightly wilted on the $\mathrm{OE}$ and $\mathrm{AC}$ plants (Fig. 2a), showing that a reduction in the transcript level of SIF3HL increased plant sensitivity to chilling stress. Levels of MDA, proline, and ion leakage are indicators of membrane damage caused by chilling stress. Although the content of MDA increased in all of the plants after chilling stress, MDA levels were significantly higher in the KD plants than in the $\mathrm{AC}$ and $\mathrm{OE}$ plants (Fig. 2c). Similarly, the electrolyte leakage levels were significantly higher in the KD plants than in the $\mathrm{AC}$ and OE plants (Fig. 2b). In contrast, proline content was significantly lower in the KD plants than in the $\mathrm{AC}$ and $\mathrm{OE}$ plants (Fig. 2d). These data indicate that SlF3HL is critical for chilling stress tolerance in tomato plants.

\section{SIF3HL is important for ROS detoxification under chilling stress}

Plants often produce large quantities of ROS upon exposure to low temperatures. To investigate whether altered redox status contributes to increased cold sensitivity in SIF3HL KD plants under chilling stress, we measured the accumulation of $\mathrm{H}_{2} \mathrm{O}_{2}$ using DAB staining $^{52}$. All transgenic and $\mathrm{AC}$ plants accumulated basal levels of $\mathrm{H}_{2} \mathrm{O}_{2}$ under normal growth conditions. After chilling stress, $\mathrm{OE}$ plants accumulated much lower levels of $\mathrm{H}_{2} \mathrm{O}_{2}$ than did $\mathrm{KD}$ plants (Fig. 3a). We also determined the levels of superoxide radicals $\left(\mathrm{O}_{2}{ }^{-}\right)$in $\mathrm{AC}$ and transgenic plants under chilling stress. Without chilling stress, there was no significant difference in $\mathrm{O}_{2}{ }^{-}$content between the $\mathrm{AC}$ and transgenic plants. However, with chilling stress, the KD plants accumulated higher levels of $\mathrm{O}_{2}{ }^{-}$than did the $\mathrm{AC}$ and $\mathrm{OE}$ plants (Fig. 3b). The 
A

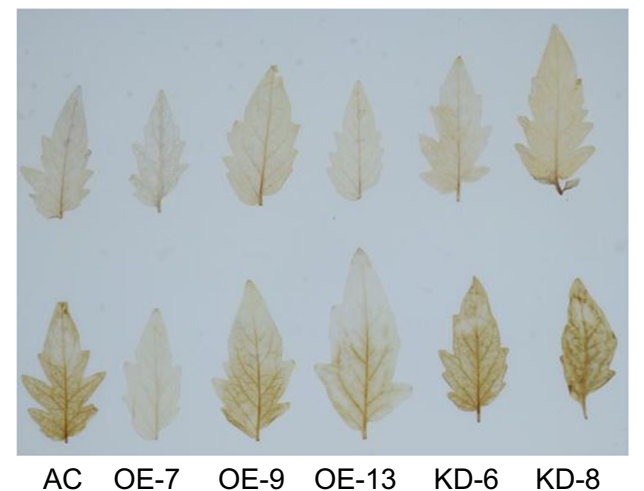

C

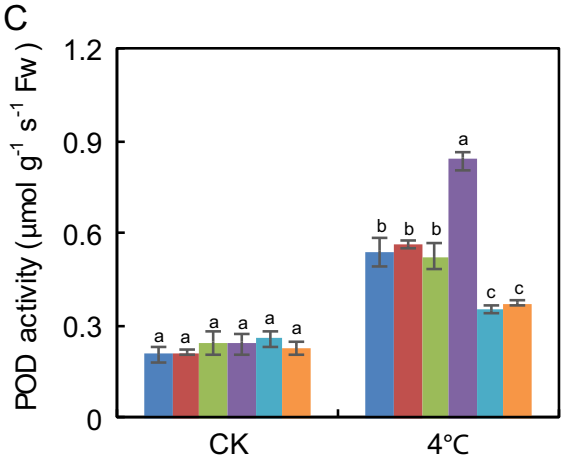

B

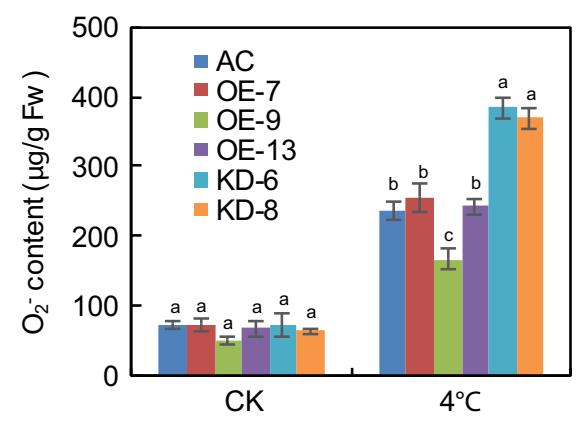

D

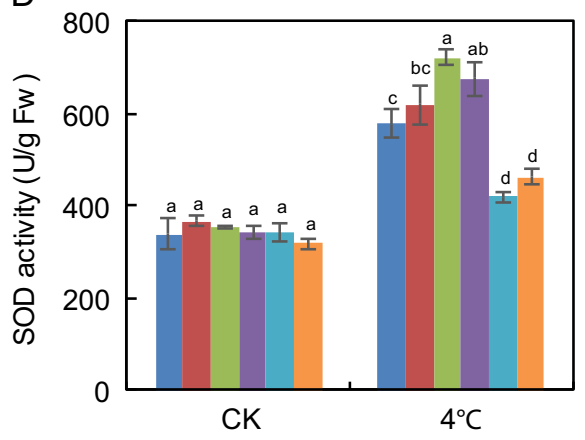

Fig. 3 SIF3HL is important for ROS scavenging under chilling stress. a 3,3'-diaminobenzidine (DAB) staining for hydrogen peroxide $\left(\mathrm{H}_{2} \mathrm{O}_{2}\right)$ in leaves from plants under normal and chilling stress conditions; $\mathbf{b}$ Levels of superoxide radical $\left(\mathrm{O}_{2}{ }^{-}\right)$in leaves from plants treated with or without chilling stress; $\mathbf{c}$ POD activity in AC and SIF3HL transgenic lines under normal and chilling stress conditions; d SOD activity in AC and SIF3HL transgenic lines under normal and chilling stress conditions. The data are presented as the mean $\pm \operatorname{SD}(n=5)$. Values with different letters under normal or chilling stress conditions significantly differ according to ANOVA and LSD tests $(p<0.05)$

accumulation of excessive ROS is the major factor leading to cell damage under abiotic stresses. Because plant cells can scavenge excessive ROS using a complex antioxidant system that includes POD and SOD, we assessed POD and SOD activities in the $\mathrm{AC}$ and transgenic plants under chilling stress. POD and SOD activities did not differ between AC and transgenic plants under normal growth conditions (Fig. 3c, d). When the plants were exposed to $4{ }^{\circ} \mathrm{C}$ for $48 \mathrm{~h}$, POD and SOD activities increased in all of the plants but were much higher in the $\mathrm{AC}$ and OE plants than in the KD plants (Fig. 3c, d). These data indicate that altered redox status may contribute to the increased sensitivity to chilling stress in KD plants.

\section{SIF3HL positively regulates cold-responsive gene expression in tomato}

To determine whether SIF3HL regulates chilling stress through the ICE-CBF pathway, we measured the transcript abundances of the ICE-CBF pathway-related genes in $\mathrm{AC}$ and transgenic plants under chilling stress. The tomato gene $S l C B F 1$ can be induced by chilling stress and can increase freezing tolerance in Arabidopsis $^{17}$.
Furthermore, overexpression of SIICE1 has been shown to enhance chilling stress tolerance in tomato ${ }^{22}$. The expression of SlICE1, SlCBF1, SlCBF3, and the SlCBF1dependent gene SIDRCi7 was investigated in the $A C$ and transgenic plants during chilling stress (Fig. 4). The expression levels of SIICE1, SlCBF1, and SlCBF3 were slightly higher in the $\mathrm{OE}$ plants than in the KD plants under normal conditions, but expression of SIDRCi7 did not significantly differ among the $\mathrm{AC}, \mathrm{OE}$, and $\mathrm{KD}$ plants under these conditions. Although the expression of these genes was upregulated in all plants after chilling stress treatment, the transcript levels of these genes were substantially higher in the $\mathrm{AC}$ and $\mathrm{OE}$ plants than in the $\mathrm{KD}$ plants (Fig. 4). These results suggest that SlF3HL may be involved in chilling tolerance regulation in tomato plants via the ICE-CBF pathway.

\section{SIF3HL regulates JA biosynthesis and controls the expression of JA biosynthesis genes and downstream JA signaling genes}

JA plays key roles in regulating plant responses to various environmental stresses ${ }^{56}$. To determine whether 

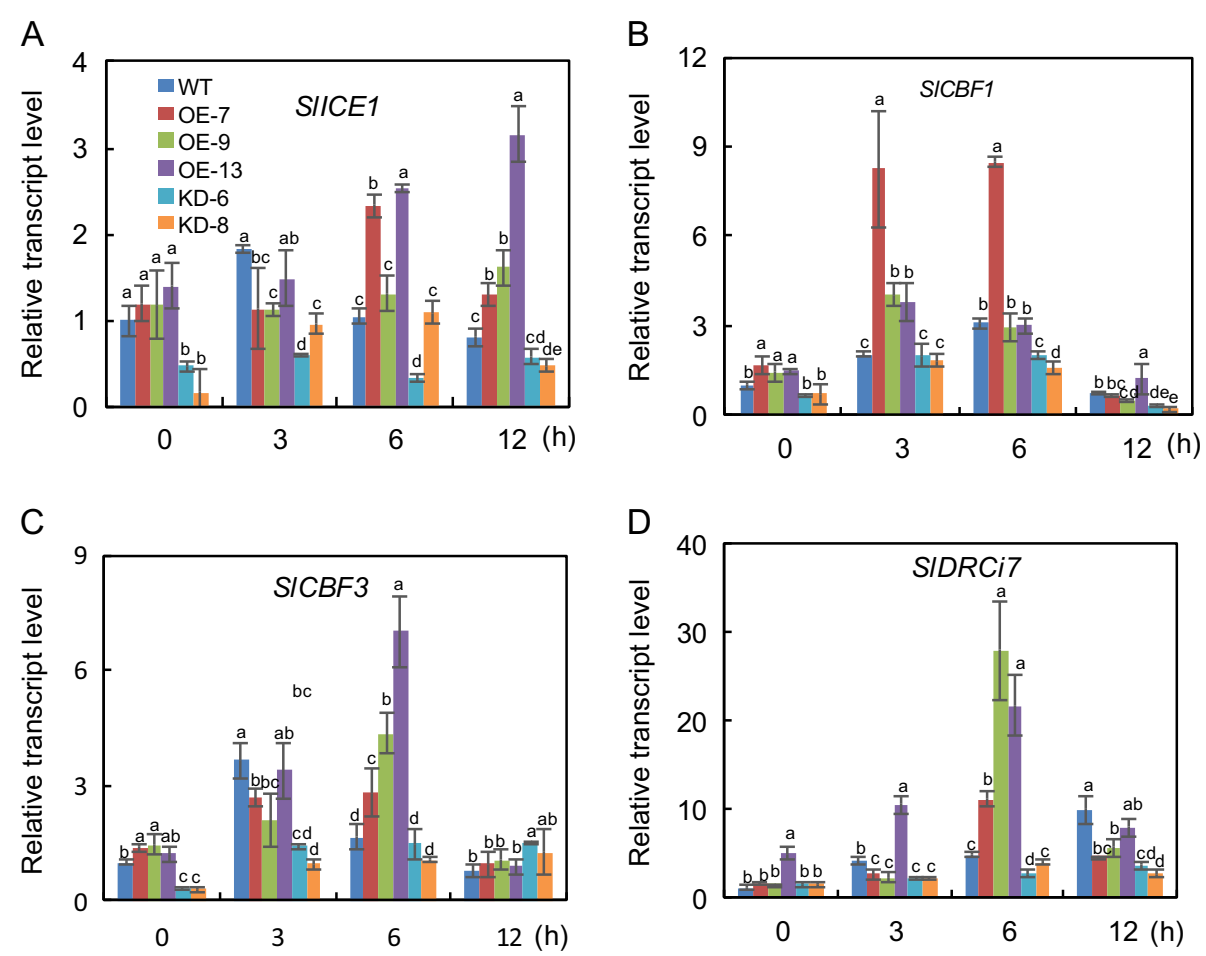

Fig. 4 Expression of four cold-responsive genes in AC and SIF3HL transgenic lines under normal and chilling stress conditions. The data are presented as the mean $\pm \mathrm{SD}(n=3)$. Values with different letters at a particular time point of chilling stress significantly differ according to ANOVA and LSD tests $(p<0.05)$

SIF3HL is involved in JA-regulated chilling stress responses in tomato, we sowed seeds of AC-generation and $\mathrm{T}_{2}$-generation transgenic plants on $1 / 2 \mathrm{MS}$ medium or $1 / 2$ MS medium containing $5 \mu \mathrm{M}$ MeJA or $10 \mu \mathrm{M}$ DIECA. The germinated seedlings were then grown for an additional 10 days with or without chilling stress. The growth of $\mathrm{AC}$ and transgenic seedlings was significantly reduced under chilling stress. However, the fresh weights, root lengths, and hypocotyl lengths of the $\mathrm{AC}$ and $\mathrm{OE}$ plants were significantly greater than those of the KD plants under chilling stress (Fig. 5). Fresh weight and primary root length were significantly greater in the AC and $\mathrm{OE}$ plants than in the $\mathrm{KD}$ plants under normal conditions with or without exogenous MeJA. Fresh weight and primary root length did not significantly differ among the $\mathrm{AC}, \mathrm{OE}$, and $\mathrm{KD}$ plants grown under normal conditions with DIECA or under chilling stress conditions with DIECA or MeJA (Fig. 5a, b). These data suggest that knockdown of SlF3HL in tomato increases sensitivity to the JA signal. Chilling stress induced the accumulation of JA, and the levels of JA were significantly lower in the KD plants than in the $\mathrm{AC}$ and $\mathrm{OE}$ plants under both normal and chilling stress conditions (Fig. 5c). These data indicate that SIF3HL regulates the level of JA accumulation under normal and chilling stress conditions.
We performed qRT-PCR analysis to determine whether the transcript levels of JA biosynthesis and signaling pathway-related genes are altered in SIF3HL KD plants under chilling stress. The transcript levels of SIAOC and SIOPR3, which are involved in the biosynthesis of JA, were substantially lower in the KD plants than in the $\mathrm{AC}$ and OE plants under both normal conditions and chilling stress conditions (Fig. 6). We also examined the transcript levels of JA signaling pathway genes (SlJAZs, SlMYC2, and SlCOI1) in the AC and SlF3HL transgenic plants. The expression of SIMYC2 was higher in the AC and $\mathrm{OE}$ plants than in the KD plants under both normal and chilling stress conditions (Fig. 6). The expression of SlCOI1 was slightly lower in the KD plants than in the AC and OE plants under normal conditions but was similar among all genotypes tested under chilling stress conditions (Fig. 6). All of the tested SlJAZs except SIJAZ1 are cold inducible. The transcript levels of SlJAZ1 were lower in the KD plants than in the $\mathrm{AC}$ and $\mathrm{OE}$ plants under normal conditions but were increased in the KD plants under chilling stress conditions (Fig. 6). In contrast, the expression levels of SIJAZ13 and SIJAZ2 were considerably higher in the KD plants than in the AC and OE plants under both normal and chilling stress conditions (Fig. 6). The two JA-responsive genes, SlPI-II and SlJMT, are cold inducible, but their expression levels were much 
A
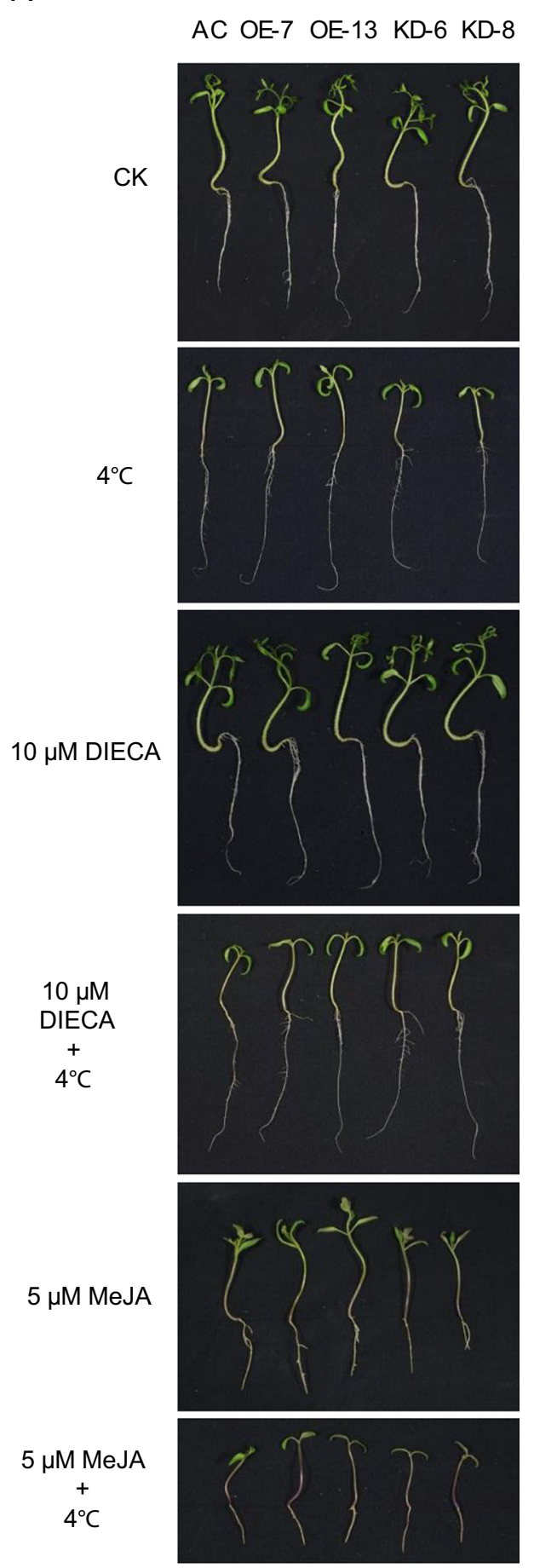

B
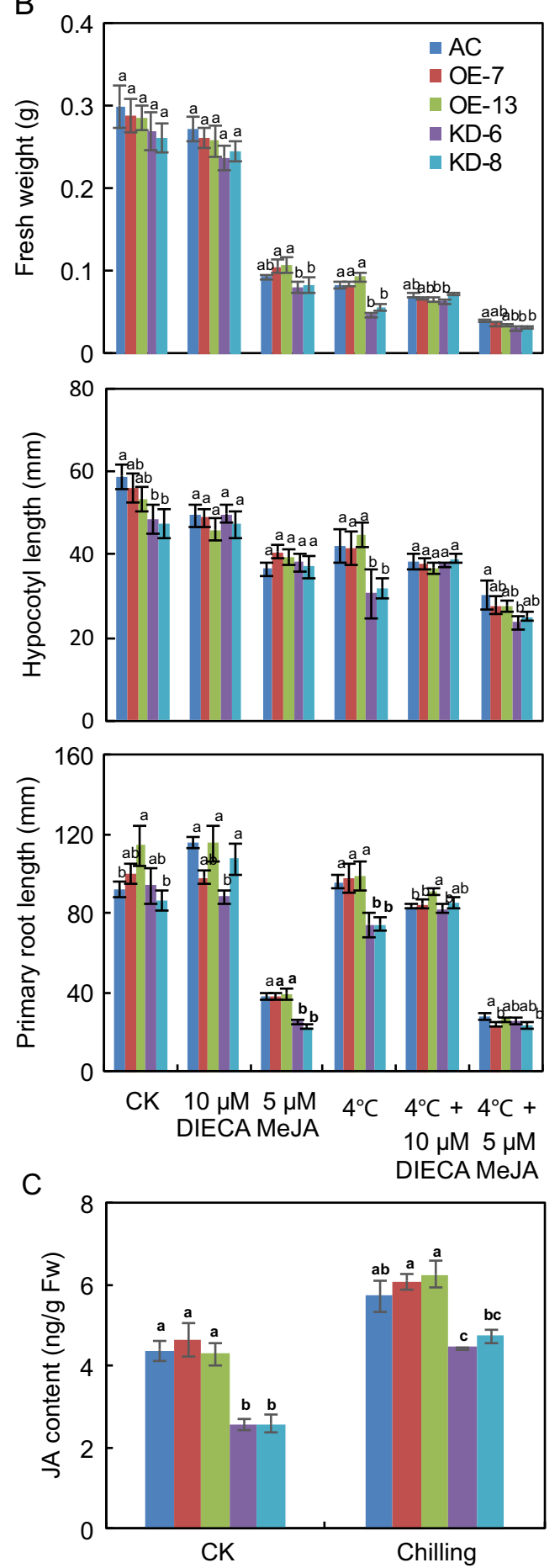

Fig. 5 SIF3HL is important for jasmonate biosynthesis under chilling stress. a Phenotypes of plants of AC and SIF3HL transgenic lines under normal and chilling stress conditions with or without MeJA or DIECA; b Fresh weights, primary root lengths, and hypocotyl lengths of plants shown in a. c Jasmonate levels in transgenic lines. The data are presented as the mean \pm SD $(n \geq 3)$. Values with different letters under a particular growth condition significantly differ according to ANOVA and LSD tests $(p<0.05)$ 

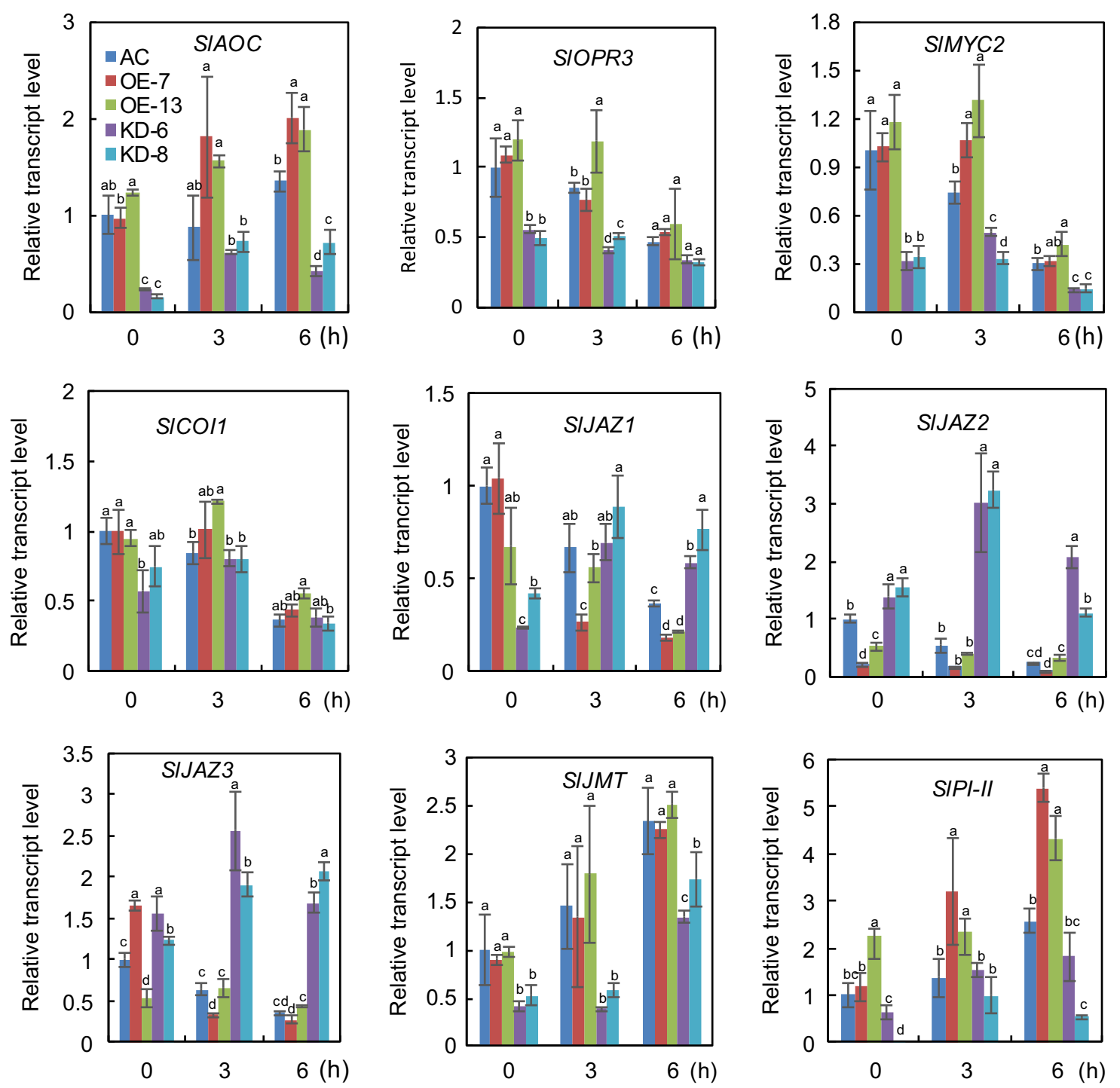

Fig. 6 Expression of JA biosynthesis and signal transduction-related genes in AC and SIF3HL transgenic lines under chilling stress. The data are presented as the mean $\pm \mathrm{SD}(n=3)$. Values with different letters at a particular time point of chilling stress significantly differ according to ANOVA and LSD tests $(p<0.05)$

lower in the $\mathrm{KD}$ plants than in the $\mathrm{AC}$ and $\mathrm{OE}$ plants (Fig. 6). Together, these data suggest that SIF3HL is involved in regulating JA accumulation under chilling stress and that it may function by altering the expression of JA biosynthetic and signaling-related genes.

\section{Discussion}

In this study, we found that the tomato gene SlF3HL contributes to chilling stress tolerance. SIF3HL belongs to the 2-OG oxygenase family, and the members of this family are involved in various biological processes including plant hormone biosynthesis ${ }^{43}$. SIF3HL has highest sequence similarity with its Arabidopsis homolog, AtDMR6 ${ }^{55}$. AtDMR6 catalyzes salicylic acid to produce 2,5-dihydroxybenzoic acid, which affects leaf senescence and the defense against Pseudomonas syringae pv tomato DC $3000^{46}$. We hypothesized that SIF3HL functions in cold stress responses because it is cold inducible. To determine the role of SlF3HL in cold stress responses, we produced loss-of-function and potential gain-of-function transgenic tomato plants. The SlF3HL knockdown plants created through RNA interference were hypersensitive to chilling stress, suggesting that SlF3HL is a positive regulator of chilling stress tolerance.

Many studies have reported that ROS production is triggered when plants are exposed to abiotic stresses ${ }^{57}$. Chilling stress can lead to the production of large amounts of ROS, which in turn can cause oxidative 
damage to DNA, proteins and membrane lipids ${ }^{58-60}$. In the present study, we found that $\mathrm{H}_{2} \mathrm{O}_{2}$ and $\mathrm{O}_{2}{ }^{-}$levels were greater in the $S l F 3 H L-K D$ plants than in the AC and SlF3HL-OE plants under chilling stress (Fig. $3 \mathrm{a}, \mathrm{b}$ ). The levels of MDA and ion leakage, which reflect the degree of cellular membrane damage, were significantly higher in the SlF3HL-KD plants than in the AC and OE plants (Fig. 2b, c). Proline is a small compatible molecule that can protect plants from abiotic stresses, including oxidative stress. Our results showed that proline content was lower in the KD plants than in the $\mathrm{AC}$ and $\mathrm{OE}$ plants under chilling stress (Fig. 2d). It is possible that the increased sensitivity of $S I F 3 H L-K D$ plants to chilling stress is at least partially caused by the alterations in these physiological parameters, i.e., by increases in ROS and MDA levels and by reductions in proline levels.

Plants have evolved complex mechanisms that involve both nonenzymatic and enzymatic antioxidants and that work in concert to scavenge overproduced ROS and protect cells during abiotic stress ${ }^{60,61}$. The enzymatic antioxidant system comprises ascorbate peroxidase, catalase, SOD, and POD, which scavenge ROS ${ }^{62}$. We found that the activities of SOD and POD were substantially lower in the KD plants than in the $\mathrm{AC}$ and $\mathrm{OE}$ plants during chilling stress (Fig. 3c, d). These data suggest that SIF3HL is important for the detoxification of ROS under chilling stress in tomato plants.

The plant hormone JA modulates many physiological processes, such as root initiation, leaf senescence, and biotic and abiotic stress responses ${ }^{32,63-65}$. Previous studies have demonstrated that exogenous JA can inhibit various aspects of seedling growth, including root growth and hypocotyl elongation ${ }^{66,67}$. In the present study, the growth of AC and SlF3HL transgenic seedlings did not significantly differ in the absence of MeJA treatment under normal conditions, but growth inhibition by MeJA treatment under normal conditions was greater for the SlF3HL-KD seedlings than for the AC and OE seedlings (Fig. 5). These results suggest that $S l F 3 H L-K D$ plants may be sensitive to JA signaling. Although growth was greater for $\mathrm{AC}$ and $\mathrm{OE}$ seedlings than for $\mathrm{KD}$ seedlings during chilling stress, growth did not significantly differ among these seedlings during chilling stress when the medium was supplemented with MeJA or the JA biosynthesis inhibitor DIECA (Fig. 5). These data suggest that SIF3HL controls chilling stress responses, possibly through the JA signaling pathway.

$A O C$ and $O P R 3$ are key enzymes in JA biosynthesis. The content of JA-Ile was shown to be significantly decreased in the opr3-3 mutant relative to wild type in tomato ${ }^{68}$. In other work, RNAi interference of SlOPR3 failed to result in accumulated JA after wounding ${ }^{69}$. The present finding that the SIF3HL-KD plants produced reduced levels of SlAOC and SIOPR3 transcripts relative to the levels in AC

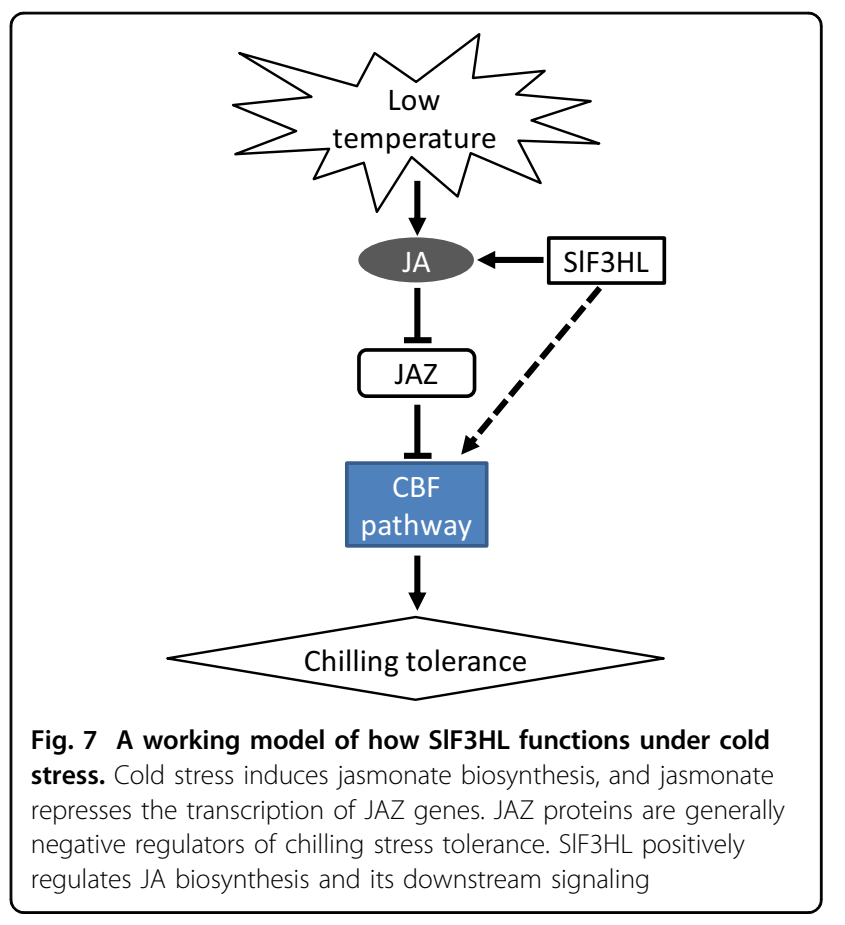

and OE plants during chilling stress (Fig. 6) suggests that SIF $3 H L$ is a positive regulator of JA biosynthesis. JAZ proteins are key transcriptional repressors of the jasmonate-sensing and jasmonate-signaling pathway and play key roles in abiotic stress responses ${ }^{70}$. COI1, JAZs, and $\mathrm{MYC} 2$ are involved in JA signaling transduction and regulate JA-induced abiotic stress responses ${ }^{40,71,72}$. In the current study, the growth of AC and SlF3HL-OE tomato seedlings was significantly greater than that of SIF3HL KD plants under normal conditions with MeJA treatment. The transcript levels of SIMYC2 in SlF3HL were significantly lower in the KD plants than in the $\mathrm{AC}$ and $\mathrm{OE}$ plants (Fig. 6). In contrast, the expression of SlJAZs was generally higher in the SlF3HL-KD plants than in the AC and $\mathrm{OE}$ plants under chilling stress (Fig. 6). These results suggest that $S I F 3 H L$ may control chilling stress tolerance in a JA-dependent manner.

Based on our results and those of previous studies of model plant species, we propose a working model of SIF3HL-regulated JA biosynthesis and downstream signaling under chilling stress (Fig. 7): SlF3HL positively regulates the level of JA under chilling stress, and JA negatively regulates the transcript levels of JAZs, resulting in enhanced chilling stress tolerance. SlF3HL also positively affects the expression of cold-responsive genes.

\section{Acknowledgements}

This work was supported by the National Natural Science Foundation of China (nos. 31701925 and 31671273), the China Postdoctoral Science Foundation (no. 2016M602876), the Natural Science Foundation of Shaanxi Province of China (no. 2017JQ3016), the Chinese Universities Scientific Fund (no. Z109021607), 
and Start-up Funds of Northwest A\&F University (nos. Z109021620 and Z111021601).

\section{Author details}

${ }^{1}$ State Key Laboratory of Crop Stress Biology for Arid Areas and College of Horticulture, Northwest A\&F University, No. 3, Taicheng Road, 712100 Yangling, Shaanxi, China. ${ }^{2}$ School of Biotechnology, Jiangsu University of Science and Technology, Zhenjiang, Jiangsu, China. ${ }^{3}$ Department of Plant Science and Landscape Architecture, College of Agriculture and Natural Resources, University of Maryland, College Park, MD 20742, USA

\section{Conflict of interest}

The authors declare that they have no conflict of interest.

Supplementary Information accompanies this paper at (https://doi.org/ 10.1038/s41438-019-0127-5).

Received: 17 October 2018 Revised: 27 January 2019 Accepted: 28 January 2019

Published online: 01 April 2019

\section{References}

1. Chinnusamy, V., Zhu, J. K. \& Sunkar, R. Gene regulation during cold stress acclimation in plants. Methods Mol. Biol. 639, 39-55 (2010).

2. Van Heerden, P. D., Strasser, R. J. \& Kruger, G. H. Reduction of dark chilling stress in $\mathrm{N}$-fixing soybean by nitrate as indicated by chlorophyll a fluorescence kinetics. Physiol. Plant. 121, 239-249 (2004).

3. Kielbowicz-Matuk, A., Rey, P. \& Rorat, T. The organ-dependent abundance of a Solanum lipid transfer protein is up-regulated upon osmotic constraints and associated with cold acclimation ability. J. Exp. Bot. 59, 2191-2203 (2008).

4. Orvar, B. L., Sangwan, V., Omann, F. \& Dhindsa, R. S. Early steps in cold sensing by plant cells: the role of actin cytoskeleton and membrane fluidity. Plant J. $\mathbf{2 3}$ 785-794 (2000).

5. Almadanim, M. C. et al. Rice calcium-dependent protein kinase OsCPK17 targets plasma membrane intrinsic protein and sucrose-phosphate synthase and is required for a proper cold stress response. Plant Cell Environ. 40, 1197-1213 (2017)

6. Domon, J. M. et al. Cell wall compositional modifications of Miscanthus ecotypes in response to cold acclimation. Phytochemistry 85, 51-61 (2013).

7. Thomashow, M. F. Plant cold acclimation: freezing tolerance genes and regulatory mechanisms. Annu. Rev. Plant Physiol. 50, 571-599 (1999).

8. Kim, D. H., Doyle, M. R., Sung, S. \& Amasino, R. M. Vernalization: winter and the timing of flowering in plants. Annu. Rev. Cell Dev. Biol. 25, 277-299 (2009).

9. Shi, Y., Ding, Y. \& Yang, S. Cold signal transduction and its interplay with phytohormones during cold acclimation. Plant Cell Physiol. 56, 7-15 (2015).

10. Zhou, M. Q., Shen, C., Wu, L. H., Tang, K. X. \& Lin, J. CBF-dependent signaling pathway: a key responder to low temperature stress in plants. Crit. Rev. Biotechnol. 31, 186-192 (2011).

11. Wang, D. Z. et al. Gene regulation and signal transduction in the ICE-CBF-COR signaling pathway during cold stress in plants. Biochemistry 82, 1103-1117 (2017).

12. An, D. et al. Cassava C-repeat binding factor 1 gene responds to low temperature and enhances cold tolerance when overexpressed in Arabidopsis and cassava. Plant Mol. Biol. 94, 109-124 (2017).

13. Park, S. et al. Regulation of the Arabidopsis CBF regulon by a complex lowtemperature regulatory network. Plant J. 82, 193-207 (2015).

14. Stockinger, E., Gilmour, S. \& Thomashow, M. Arabidopsis thaliana CBF1 encodes an AP2 domain-containing transcriptional activator that binds to the C-repeat/DRE, a cis-acting DNA regulatory element that stimulates transcription in response to low temperature and water deficit. Proc. Natl Acad. Sci. USA 94, 1035-1040 (1997)

15. Zarka, D. G., Vogel, J. T., Cook, D. \& Thomashow, M. F. Cold induction of Arabidopsis CBF genes involves multiple ICE (inducer of CBF expression) promoter elements and a cold-regulatory circuit that is desensitized by low temperature. Plant Physiol. 133, 910-918 (2003).

16. Novillo, F., Alonso, J. M., Ecker, J. R. \& Salinas, J. CBF2/DREB1C is a negative regulator of CBF1/DREB1B and CBF3/DREB1A expression and plays a central role in stress tolerance in Arabidopsis. Proc. Natl Acad. Sci. USA 101, 3985-3990 (2004).
17. Zhang, $X$. et al. Freezing-sensitive tomato has a functional CBF cold response pathway, but a CBF regulon that differs from that of freezing-tolerant Arabidopsis. Plant J. 39, 905-919 (2004).

18. Barrero-Gil, J., Huertas, R., Rambla, J. L., Granell, A. \& Salinas, J. Tomato plants increase their tolerance to low temperature in a chilling acclimation process entailing comprehensive transcriptional and metabolic adjustments. Plant Cell Environ. 39, 2303-2318 (2016).

19. Kim, Y., Lee, M., Lee, J., Lee, H. \& Park, C. The unified ICE-CBF pathway provides a transcriptional feedback control of freezing tolerance during cold acclimation in Arabidopsis. Plant Mol. Biol. 89, 187-201 (2015).

20. Chinnusamy, V. et al. ICE1: a regulator of cold-induced transcriptome and freezing tolerance in Arabidopsis. Gene Dev. 17, 1043-1054 (2003).

21. Fursova, O. V., Pogorelko, G. V. \& Tarasov, V. A. Identification of ICE2, a gene involved in cold acclimation which determines freezing tolerance in Arabidopsis thaliana. Gene 429, 98-103 (2009).

22. Miura, K. et al. SIICE1 encoding a MYC-type transcription factor controls cold tolerance in tomato, Solanum lycopersicum. Plant Biotechnol. 29, 253-260 (2012).

23. Dong, C., Agarwal, M., Zhang, Y., Xie, Q. \& Zhu, J. The negative regulator of plant cold responses, HOS1, is a RING E3 ligase that mediates the ubiquitination and degradation of ICE1. Proc. Natl Acad. Sci. USA 103, 8281-8286 (2006).

24. Lee, $\mathrm{H}$. et al. The Arabidopsis HOS1 gene negatively regulates cold signal transduction and encodes a RING finger protein that displays cold-regulated nucleo-cytoplasmic partitioning. Gene Dev. 15, 912-924 (2001).

25. Ding, $Y$. et al. OST1 kinase modulates freezing tolerance by enhancing ICE1 stability in Arabidopsis. Dev. Cell 32, 278-289 (2015).

26. Zhan, X., Zhu, J. K. \& Lang, Z. Increasing freezing tolerance: kinase regulation of ICE1. Dev. Cell 32, 257-258 (2015).

27. Zhao, C. et al. MAP kinase cascades regulate the cold response by modulating ICE1 protein stability. Dev. Cell 43, 618-629 (2017).

28. Peleg, Z. \& Blumwald, E. Hormone balance and abiotic stress tolerance in crop plants. Curr. Opin. Plant Biol. 14, 290-295 (2011).

29. Zhu, J. K. Abiotic stress signaling and responses in plants. Cell 167, 313-324 (2016).

30. Kazan, K. Diverse roles of jasmonates and ethylene in abiotic stress tolerance. Trends Plant Sci. 20, 219-229 (2015).

31. Wasternack, C. \& Strnad, M. Jasmonate signaling in plant stress responses and development_active and inactive compounds. New Biotechnol. 33, 604-613 (2016).

32. Christensen, S. A. et al. The maize lipoxygenase, ZmLOX10, mediates green leaf volatile, jasmonate and herbivore-induced plant volatile production for defense against insect attack. Plant J. 74, 59-73 (2013).

33. Zhou, Z. et al. An Arabidopsis plasma membrane proton ATPase modulates JA signaling and is exploited by the Pseudomonas syringae effector protein AvrB for stomatal invasion. Plant Cell 27, 2032-2041 (2015).

34. Ahmad, P. et al. Jasmonates: multifunctional roles in stress tolerance. Front. Plant Sci. 7, 813 (2016).

35. Thines, B. et al. JAZ repressor proteins are targets of the SCF(COI1) complex during jasmonate signalling. Nature 448, 661-665 (2007).

36. Chen, Q. et al. The basic helix-loop-helix transcription factor MYC2 directly represses PLETHORA expression during jasmonate-mediated modulation of the root stem cell niche in Arabidopsis. Plant Cell 23, 3335-3352 (2011).

37. Song, S. et al. The Jasmonate-ZIM domain proteins interact with the R2R3MYB transcription factors MYB21 and MYB24 to affect Jasmonate-regulated stamen development in Arabidopsis. Plant Cell 23, 1000-1013 (2011).

38. Hu, Y., Jiang, L., Wang, F. \& Yu, D. Jasmonate regulates the inducer of cbf expression-C-repeat binding factor/DRE binding factor 1 cascade and freezing tolerance in Arabidopsis. Plant Cell 25, 2907-2924 (2013).

39. Seo, J. S. et al. OsbHLH148, a basic helix-loop-helix protein, interacts with OsJAZ proteins in a jasmonate signaling pathway leading to drought tolerance in rice. Plant J. 65, 907-921 (2011).

40. Wu, H., Ye, H., Yao, R., Zhang, T. \& Xiong, L. OsJAZ9 acts as a transcriptional regulator in jasmonate signaling and modulates salt stress tolerance in rice. Plant Sci. 232, 1-12 (2015).

41. Du, H., Liu, H. \& Xiong, L. Endogenous auxin and jasmonic acid levels are differentially modulated by abiotic stresses in rice. Front. Plant Sci. 4, 397 (2013).

42. Wang, F. et al. Phytochrome A and B function antagonistically to regulate cold tolerance via abscisic acid-dependent jasmonate signaling. Plant Physiol. 170, 459-471 (2016)

43. Kawai, Y., Ono, E. \& Mizutani, M. Evolution and diversity of the 2-oxoglutaratedependent dioxygenase superfamily in plants. Plant J. 78, 328-343 (2014). 
44. Hedden, P. \& Thomas, S. G. Gibberellin biosynthesis and its regulation. Biochem. J. 444, 11-25 (2012)

45. Zeilmaker, T. et al. DOWNY MILDEW RESISTANT 6 and DMR6-LIKE OXYGENASE 1 are partially redundant but distinct suppressors of immunity in Arabidopsis. Plant J. 81, 210-222 (2015).

46. Zhang, Y. et al. S5H/DMR6 encodes a salicylic acid 5-hydroxylase that finetunes salicylic acid homeostasis. Plant Physiol. 175, 1082-1093 (2017).

47. Livak, K. J. \& Schmittgen, T. D. Analysis of relative gene expression data using real-time quantitative PCR and the 2(-Delta Delta $C(T)$ ) method. Methods 25, 402-408 (2001).

48. Cao, W. H. et al. Modulation of ethylene responses affects plant salt-stress responses. Plant Physiol. 143, 707-719 (2007).

49. Cui, Y. \& Wang, Q. Physiological responses of maize to elemental sulphur and cadmium stress. Plant Soil Environ. 52, 523-529 (2006).

50. Bates, L. S., Waldren, R. P. \& Teare, I. D. Rapid determination of free proline for water-stress studies. Plant Soil 39, 205-207 (1973).

51. Able, A. J., Guest, D. I. \& Sutherland, M. W. Use of a new tetrazolium-based assay to study the production of superoxide radicals by tobacco cell cultures challenged with avirulent zoospores of phytophthora parasitica var nicotianae. Plant Physiol. 117, 491-499 (1998).

52. Lee, B. H., Lee, H., Xiong, L. \& Zhu, J. K. A mitochondrial complex I defect impairs cold-regulated nuclear gene expression. Plant Cell 14, 1235-1251 (2002).

53. Ye, N. et al. Ascorbic acid and reactive oxygen species are involved in the inhibition of seed germination by abscisic acid in rice seeds. J. Exp. Bot. 63, 1809-1822 (2012).

54. Muller, M. \& Munne-Bosch, S. Rapid and sensitive hormonal profiling of complex plant samples by liquid chromatography coupled to electrospray ionization tandem mass spectrometry. Plant Methods 7, 37 (2011).

55. Meng, C., Zhang, S., Deng, Y. S., Wang, G. D. \& Kong, F. Y. Overexpression of a tomato flavanone 3-hydroxylase-like protein gene improves chilling tolerance in tobacco. Plant Physiol. Biochem. 96, 388-400 (2015).

56. Sharma, M. \& Laxmi, A. Jasmonates: emerging players in controlling temperature stress tolerance. Front. Plant Sci. 6, 1129 (2015).

57. Suzuki, N., Koussevitzky, S., Mittler, R. \& Miller, G. ROS and redox signalling in the response of plants to abiotic stress. Plant Cell Environ. 35, 259-270 (2012).
58. Vanacker, H. et al. Roles for redox regulation in leaf senescence of pea plants grown on different sources of nitrogen nutrition. J. Exp. Bot. 57, 1735-1745 (2006).

59. Apel, K. \& Hirt, H. Reactive oxygen species: metabolism, oxidative stress, and signal transduction. Annu. Rev. Plant Biol. 55, 373-399 (2004).

60. Choudhury, F. K., Rivero, R. M., Blumwald, E. \& Mittler, R. Reactive oxygen species, abiotic stress and stress combination. Plant J. 90, 856-867 (2017).

61. Mittler, R. ROS are good. Trends Plant Sci. 22, 11-19 (2017).

62. Mittler, R., Vanderauwera, S., Gollery, M. \& Van Breusegem, F. Reactive oxygen gene network of plants. Trends Plant. Sci. 9, 490-498 (2004).

63. Smirnova, E. et al. Jasmonic acid oxidase 2 hydroxylates jasmonic acid and represses basal defense and resistance responses against Botrytis cinerea infection. Mol. Plant 10, 1159-1173 (2017).

64. Caarls, L. et al. Arabidopsis jasmonate-induced oxygenases down-regulate plant immunity by hydroxylation and inactivation of the hormone jasmonic acid. Proc. Natl Acad. Sci. USA 114, 6388-6393 (2017).

65. $\mathrm{Hu}, \mathrm{Y}$. et al. Jasmonate regulates leaf senescence and tolerance to cold stress: crosstalk with other phytohormones. J. Exp. Bot. 68, 1361-1369 (2017).

66. Zheng, Y. et al. Jasmonate inhibits COP1 activity to suppress hypocotyl elongation and promote cotyledon opening in etiolated Arabidopsis seedlings. Plant J. 90, 1144-1155 (2017).

67. Chen, H. J., Chen, C. L. \& Hsieh, H. L. Far-red light-mediated seedling development in Arabidopsis involves Far-red insensitive 219/jasmonate resistant 1dependent and -independent pathways. PLOS ONE 10, e0132723 (2015).

68. Chini, A. et al. An OPR3-independent pathway uses 4,5-didehydrojasmonate for jasmonate synthesis. Nat. Chem. Biol. 14, 171-178 (2018).

69. Bosch, M. et al. Jasmonic acid and its precursor 12-oxophytodienoic acid control different aspects of constitutive and induced herbivore defenses in tomato. Plant Physiol. 166, 396-410 (2014).

70. Chini, A. et al. The JAZ family of repressors is the missing link in jasmonate signalling. Nature 448, 666-671 (2007).

71. Nagels Durand, A., Pauwels, L. \& Goossens, A. The ubiquitin system and jasmonate signaling. Plants (Basel) 5, 6 https://doi.org/10.3390/plants5010006 (2016).

72. Chung, H. S. et al. Alternative splicing expands the repertoire of dominant JAZ repressors of jasmonate signaling. Plant J. 63, 613-622 (2010). 